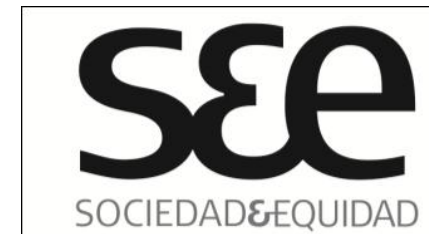

\section{Resistencias y conflictos socioambientales en Tandil. Un estudio de caso}

Resistance and environmental conflicts in Tandil. A case

\author{
Agustina Girado (1) \\ Universidad Nacional del Centro \\ de la Provincia de Buenos Aires. \\ Argentina \\ giradoagustina@yahoo.com.ar
}

\title{
RESUMEN
}

En las últimas décadas la "cuestión ambiental" se ha transformado en un tema de interés público. Su inscripción en los discursos y prácticas de una gran diversidad de actores sociales y la fuerte presencia de la temática en los debates políticos, económicos y culturales permite interpretar su lugar en la agenda pública. Asimismo, en sintonía con el crecimiento de los conflictos socioambientales en América Latina, se van gestando diversas resistencias sociales que ponen en cuestionamiento las narrativas hegemónicas del discurso desarrollista y sus implicaciones en las políticas subsidiarias. En este contexto, el presente artículo reflexiona sobre el conflicto socioambiental surgido en una ciudad media de la Argentina en torno al uso, gestión y ocupación de un recurso natural, donde diversos actores se enfrentan en una arena de plurales significados y prácticas. Al mismo tiempo, se pone de manifiesto cómo el conflicto se fue resignificando y adquiriendo nuevas aristas a la luz de los intereses políticos y económicos que gravitan en el manejo del medio ambiente. La totalidad de estas reflexiones se enmarcan en la investigación antropológica llevada adelante entre los años 2009 y 2011 en la ciudad de Tandil, Provincia de Buenos Aires, desde una perspectiva etnográfica.

\section{PALABRAS CLAVES}

Medio ambiente, conflictos socioambientales, resistencias sociales, desarrollo, Tandil.

\footnotetext{
${ }^{1}$ La autora es Licenciada en Antropología Social de la Facultad de Ciencias Sociales de Olavarría en la Universidad Nacional del centro de la Provincia de Buenos Aires, (UNICEN). Sus líneas de investigación son: Problemáticas Socioambientales Urbanas y Salud Ambiental.
} 


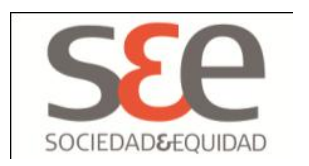

\begin{abstract}
In the last few decades the "environmental issue" has been transformed in a matter of public interest. Its inscription in the discourses and practices of a great diversity of social actors and the strong presence of the subject matter in the cultural, economic, and political debates makes it possible to interpret its place in the public agenda. Also, as the social-environmental conflicts in Latin America grow, many social resistances rise that question the hegemonic narratives of the developmental discourse and their implications in subsidiary policies. In this context, this article reflects on the social-environmental conflict that has emerged in a middle-sized city of Argentina about the use, management and occupation of a natural resource, where different actors confront in an arena with plural meanings and practices. At the same time, it highlight how the conflict has been re-signified and has acquired new edges in the light of political and economic interests that gravitate in the environmental management. All these reflections are based on anthropological research carried forward between 2009 and 2011 in the city of Tandil, a province of Buenos Aires, from an ethnographic perspective.
\end{abstract}

\title{
KEYWORDS
}

Environment, social-environmental conflicts, social resistances, development,Tandil.

\section{Introducción}

El origen de las problemáticas ambientales posee una complejidad intrínseca que requiere múltiples miradas para su análisis, además de la posibilidad de desarrollar nuevos marcos conceptuales. Desde una perspectiva antropológica este abordaje implica considerar la configuración sociohistórica de lo ambiental como problema.

Durante las últimas décadas, en el contexto latinoamericano la conjunción de ciertos factores ha permitido generar un creciente interés por las formas de interacción, apropiación y utilización que las diferentes sociedades realizan de su entorno natural, así como también de las consecuencias que se derivan de ello.

El abordaje de conflictos y movimientos socioambientales en Argentina resulta una temática novedosa y relativamente reciente. Los conflictos socioambientales ocupan un papel central en la historia ambiental de nuestro país, ya que permiten visibilizar los enfrentamientos entre diferentes dinámicas de apropiación de los territorios y sus recursos. Las confrontaciones producidas entre diversos sujetos por el acceso y control de los recursos naturales, así como también la distribución 


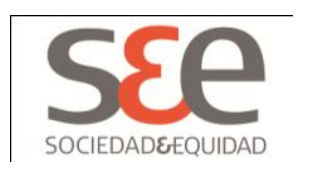

desigual de beneficios y externalidades generados a partir de determinadas actividades productivas, deben ser interpretados en al marco general de los conflictos socioambientales (Orellana, 1999; Sabatini, 1997; Walter, 2009).

Los conflictos socioambientales son primordialmente conflictos territoriales, distributivos y políticos. Estos permiten visualizar las limitaciones tanto del accionar del Estado como de su razón técnico-instrumental basada en la fe científica y tecnológica, generando nuevos espacios de resistencia, formas de organización y participación social.

En la Argentina la aparición o visibilización pública de numerosos movimientos, organizaciones u ONGs se vincula con la crisis del $2001^{2}$. El contexto económico, político y social de la década del ' 90 fue crucial para el surgimiento de nuevas modalidades de participación social. Las políticas neoliberales implementadas por el Estado impactaron negativamente en la gestión del medio ambiente y brindaron un marco de pobreza y pauperización estructural que hizo mella en los sectores marginales y periféricos. La crisis del 2001 posibilitó que se multiplicaran las organizaciones y ONGs, se ampliaran los temas y demandas de los actores movilizados y se generaran nuevos espacios de protesta, donde en algunos casos la defensa por el medio ambiente se acopló a las formas tradicionales de resistencia social (demanda de salario digno, educación pública, gratuita y de calidad, renovación política, etc.). En este sentido, las principales protestas que manifestaron esta articulación en la post-crisis fueron: la ciudad de Esquel en los años 2002- 2003 contra la actividad minera, y los habitantes de Gualeguaychú en el año 2005 contra

\footnotetext{
2 "La crisis argentina de fines de 2001 y principios de 2002 puede ser entendida como el desenlace de un largo proceso de descomposición de algunos de los pilares que habían sostenido el orden político y social de la década anterior. En primer lugar, encontramos el fin de la norma fundamental del ordenamiento económico de los 90: la Ley de Convertibilidad. Esta política formó parte de un conjunto mayor de reformas de corte neoliberal cuyo fin principal fue el de reducir el rol del Estado tanto en sus funciones como en sus capacidades, autolimitando las posibilidades de acción autónoma del aparato estatal (...). En segundo lugar, y claramente vinculado con lo anterior, en los 90 se debilitó el paradigma de la sociedad argentina como una estructura con movilidad ascendente, con acotados márgenes de pobreza y con un Estado comprometido con la reducción de la marginalidad y la exclusión. La indiferencia estatal ante estas problemáticas coadyuvó, indudablemente, con el estallido social ocurrido los días 19 y 20 de Diciembre de 2001. Finalmente, en la década pasada se incubó un proceso de desafección social hacia la política, que también influyó en esos acontecimientos. La autorreferencialidad de la política, las generalizadas sospechas de corrupción y la falta de decisión política para tomar medidas que contrariaran al aparentemente todopoderoso "mercado", generaron un clima de apatía o directa hostilidad hacia los principales partidos políticos, los cuales, con la excepción parcial del Justicialismo, fueron duramente castigados en los comicios de 2001." (Aval Medina, 2006:1)
} 


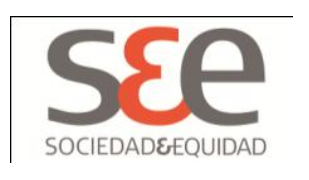

la instalación de dos grandes plantas de fabricación de pasta celulósica (Scribano y Schuster, 2001; Cotarelo, 2005; Cotarelo e Iñigo Carrera, 2004).

En este marco, el presente artículo abordará una problemática socioambiental generada en la ciudad de Tandil (Provincia de Buenos Aires) donde distintos actores colectivos se enfrentan por la apropiación de un recurso natural sobre la base de disímiles valoraciones y prácticas. En este caso, la dimensión ambiental y, más específicamente, el uso, gestión y ocupación del sistema serrano de Tandilia se transforma en un elemento de disputa, argumentación, legitimación y negociación entre diferentes grupos de la sociedad y sectores del Estado. La reconstrucción del caso de estudio mostrará tanto las condiciones materiales que permiten el surgimiento del conflicto como la construcción subjetiva y colectiva del mismo.

\section{Surgimiento y contextualización de la temática ambiental}

En el contexto internacional, la problemática ambiental se posiciona como un aspecto relevante en la agenda de los países centrales, principalmente Estados Unidos y la Unión Europea, a raíz de las consecuencias generadas por la fuerte e irreparable dinámica productiva capitalista y los nuevos paquetes tecnológicos desarrollados en el marco de los procesos de modernización de las sociedades.

La creciente "ambientalización"3 de la vida social debe remontarse a la década del '70, momento histórico en que el ecologismo/ambientalismo adquirió visibilidad y repercusión mundial. En este sentido, la naturaleza se convierte en referente político, objeto de disputa y apropiación, en tanto emergen nuevos movimientos socioambientales y corrientes teóricas que dejan de visualizarla como un objeto a ser dominado y desmembrado para pasar a ser un sujeto de derecho, resignificado y reapropiado.

Los aportes de Martínez Alier fueron fundamentales para entender que el ambientalismo, con sus diferentes nombres, no resulta un fenómeno nuevo. Este posee múltiples raíces y su diversidad está dada por las características locales de las problemáticas, las cuales cobran importancia a la luz de la creciente degradación del medio ambiente, de la conciencia masiva de ello y de que se constituyen en un elemento de disputa político-económica (Sarlingo, 2001).

El ambientalismo, como lo menciona Enrique Leff (1986), busca transformar las relaciones de poder, construir una nueva racionalidad productiva, y generar modelos alternativos de desarrollo sobre la base de la autogestión comunitaria de los

\footnotetext{
${ }^{3}$ El proceso de creciente ambientalización de la vida social está vinculado a procesos previos de devastación y, además, da cuenta de un cambio en las demandas de sectores subalternos y presenta un campo de luchas donde son puestos en tensión diferentes modelos de desarrollo con sus múltiples dimensiones, niveles y representaciones (Leite Lopes , 2006).
} 


\section{SEe}

recursos, la aplicación de tecnologías adecuadas y el respeto a los valores culturales. En la actualidad se ha producido una conciencia colectiva de la problemática ambiental; sin embargo, esta situación no puede ser trasladada linealmente a los procesos de movilización social. En este sentido, la fuerza del ambientalismo no se localiza en una efectiva transformación de las relaciones de poder y del orden económico mundial, sino en un discurso crítico (posición ideológica-cultural) que da cuenta de una nueva relación entre el ser humano y su entorno natural. Asimismo, si bien se asiste a un proceso de "ambientalización", persiste la representación de "lo ambiental" como temática secundaria y subordinada a la economía de mercado.

El movimiento ambientalista/ecologista forma parte de los "nuevos movimientos sociales". Estos se estructuran en la esfera de la reproducción, son multisectoriales, policlasistas, aprovechan las nuevas tecnologías de comunicación innovando en la manifestación de sus símbolos y formas de protesta no convencionales, poseen amplitud de objetivos y orientación emancipadora (Castells, 1987; Giner, 2004; Gravano, 2005).Asimismo, tales movimientos se definen en oposición a los movimientos clásicos cuyos reclamos se constituyen en la esfera de la producción, apuntan a la toma del poder y al manejo del Estado.

En este sentido, Manuel Castells (1998) menciona que la diversidad y la pluralidad de acciones y de propuestas creativas permiten considerar al ambientalismo como un nuevo movimiento social. De este modo, Castells destaca que la mayor parte del éxito del ambientalismo radica en su capacidad de adaptación a las nuevas condiciones de comunicación y movilización en el nuevo paradigma informacional, permitiéndoles dar a conocer las problemáticas ambientales, inducir a una mayor participación y articular acciones a escala global-local.

Si bien esta caracterización del ambientalismo/ecologismo lo describe como un fenómeno ambivalente y poco uniforme política e ideológicamente, sus diversas expresiones permiten demostrar que el capitalismo no puede ser viable y sustentable ecológicamente. La crisis ambiental pone en evidencia cómo el capital destruye sus propias bases productivas.

\section{La política ambiental en América Latina}

La sensibilidad ambiental que se fue gestando en la segunda parte del siglo XX tuvo implicancias en América Latina. Durante este período se empiezan a organizar los primeros ordenamientos marcos de legislación ambiental. Sin embargo, estas pautas legislativas buscaban garantizar y legitimar nuevas formas de apropiación de los recursos naturales por parte del capital, lejos de generar una efectiva gestión ambiental de los territorios (Alimonda, 2008). 


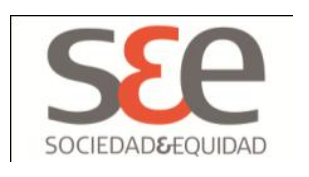

La implementación del modelo neoliberal en América Latina durante los '90 modificó abruptamente la política ambiental, ya que se definieron las condiciones de apropiación y usufructo de la naturaleza. A consecuencia de la explotación intensiva de los recursos naturales, orientada a la exportación y, en gran medida, bajo control del capital trasnacional, se desarrollaron diversos conflictos y movimientos sociales en defensa del medio ambiente y las poblaciones afectadas: “(...) lo ambiental se constituyó en un predicado con presencia real en el ámbito de las luchas por la producción de significaciones, precisamente a partir de su universalismo evidente y su carácter omnímodo" (Alimonda, 2008: 15).

En lo que respecta a la historia ambiental en Argentina, el abordaje de estas problemáticas fue de manera discontinua y fragmentaria. A comienzo de los años 70 , durante el último gobierno de Juan Domingo Perón, se formalizó el tratamiento de la temática ambiental a partir de la creación de la Secretaría de Recursos Naturales y Ambiente Humano. Con la llegada de la última dictadura cívico-militar en 1976 los avances que se habían producido en materia ambiental se lapidaron y Argentina quedó al margen de los debates internacionales respecto a la problemática. Para 1986, ya en democracia, se visualizó un cambio a partir de la creación de la Subsecretaría de Política Ambiental dentro de la jurisdicción de la Secretaría de Estado General de la Presidencia, y posteriormente se conformó la Comisión Nacional de Política Ambiental, la cual se encuentra íntimamente vinculada con los impactos que generó la difusión del Informe Brundtland ${ }^{4}$. La creación de este organismo estatal buscaba una mejor administración y uso racional de los recursos naturales, no obstante no logró garantizar la resolución de las problemáticas ambientales debido a la superposición de jurisdicciones, el incumplimiento de normativas, la debilidad de los controles y la falta de transectorialidad de las políticas ambientales (Sarlingo, 2001).

Con la posterior presidencia de Carlos Menem (1989-1999) la temática ambiental pierde importancia, diluyéndose áreas estatales específicas, pero al mismo tiempo se reproduce en el discurso hegemónico la importancia de adherir al paradigma del desarrollo sustentable. Este concepto comienza a popularizarse como nueva ideología del desarrollo, susceptible de satisfacer necesidades de las generaciones presentes sin comprometer la capacidad de las generaciones futuras para satisfacer sus propias necesidades (Gudynas, 2004).

\footnotetext{
4"Nuestro futuro común" es el nombre original del informe socio-económico elaborado por la Comisión Brundtland para la ONU en 1987. Este informe introduce el papel relevante de la pobreza y de las poblaciones desposeídas en la degradación de los recursos naturales, el control de las fuerzas del mercado en los procesos de desarrollo, la noción de desarrollo sustentable y la equidad intergeneracional y planetaria.
} 


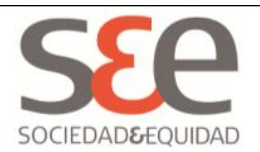

A partir de un discurso neoliberal se legitimó la privatización de los recursos naturales y el ajuste estructural en gran parte de las sociedades latinoamericanas, opacándose los procesos de dependencia, la desregulación económica, el ajuste fiscal y los marcos regulatorios que favorecían los intereses de los grandes capitales privados. La aplicación de políticas de corte neoliberal posibilitaron que el mercado y los capitales privados ocupen un papel central en el manejo de los recursos naturales. La naturaleza se visualizó como capital y su conservación como una forma más de inversión, promoviéndose la elaboración de políticas y normativas acordes a los requerimientos del mercado (Gudynas, 1998).

Más recientemente en la historia de nuestro país, con los gobiernos de Néstor Kirchner (2003-2007) y Cristina Fernández de Kirchner (2007 a la actualidad), la situación medioambiental no sufrió cambios estructurales. Siguiendo a Svampa (2008), tres son los modelos de desarrollo que prevalecen y caracterizan a la Argentina contemporánea: agrario, industrial y extractivo-exportador. Desde la Secretaría de Ambiente y Desarrollo Sustentable de la Nación se legitima un discurso utilitarista y economicista del medio ambiente. Los impactos ambientales que se derivan de la apropiación y utilización por parte del capital resultan minimizados y/o ignorados dentro de la propia lógica del mercado. Sumado a ello, se confecciona una agenda de temas de intervención prioritaria en donde figuran las energías renovables, la cuenca Matanza-Riachuelo y la educación ambiental como las temáticas en las cuales actualmente trabaja el Estado, quedando muy lejos de cumplir con las tareas aceptadas en el marco del régimen internacional de política ambiental y recomendadas por documentos internacionales, por ejemplo Agenda XXI:

(...) el diagnóstico y la evaluación permanente del estado de los recursos naturales, de los ecosistemas de su territorio y de las condiciones de vida de los conjuntos sociales; la innovación jurídica y legislativa, incluyendo el desarrollo de instrumentos concretos de regulación; el control y la vigilancia socioambiental (que en la mayoría de los casos significa organizar un sistema de cruzamiento de datos que ya tienen sus bases en la sistematización que realiza cada departamento o secretaría del aparato estatal); la formulación de una visión ambientalista de políticas, planes y programas para sectores específicos; y la coordinación de políticas generales con otros sectores relevantes: educadores, empresarios, dirigentes vecinales, etc. (Sarlingo, 2008: 166).

Durante las últimas décadas, el desarrollo de diversas actividades productivas que atentan contra el medio ambiente y las poblaciones ha generado fuertes resistencias sociales y movilizaciones a lo largo del territorio nacional. El crecimiento 


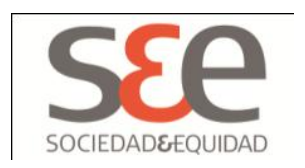

exponencial de los conflictos socioambientales, conjuntamente con el surgimiento o visibilización pública de numerosos movimientos ambientalistas y ONGs ocurre principalmente después de la post-crisis 2001.

La importancia de estos actores no se define únicamente en términos cuantitativos sino en cómo intervienen en la visibilizaciónde las problemáticas ambientales, posibilitando la defensa por y desde el territorio, la politización de las acciones y discursos, la redefinición de la agenda pública, la sanción de nuevas políticas ambientales, la recuperación de espacios públicos, el pasaje de una democracia representativa a una participativa, y la construcción de una identidad colectiva sobre la base de la protesta social. El "devenir ambientalista" en Argentina no es concebido por la mayoría de las agrupaciones y ONGs como una "opción", sino como resultado de una reacción defensiva del medio ambiente y las poblaciones que poco a poco se va cargando de otros registros colectivos y simbólicos, y que en sus estallidos "rompen los escenarios naturalizados procurando 'hacer ver' lo que se muestra como invisible, 'hacer sentir' aquello que, de tanto 'sentirlo', torna a los cuerpos insensibles" (Svampa, 2009:221).

\section{Tandil "ciudad de las sierras": posiciones en conflicto}

En la ciudad de Tandil, provincia de Buenos Aires, durante las últimas décadas se produjo un conflicto socioambiental entre diversos sectores de la sociedad civil (agrupaciones ambientalistas, vecinos pertenecientes a determinados barrios de la ciudad, representantes del sector inmobiliario y del sector minero) en torno a la utilización, gestión y ocupación del sistema serrano de Tandilia ${ }^{5}$, cuyo detonante se vinculó a la actividad minera. El crecimiento urbano hacia zonas serranas ocasionó que las canteras quedaran próximas a los límites del casco urbano de la ciudad, generando impactos sociales, económicos y ambientales. En los últimos años, la representación a nivel local y regional de Tandil como la "ciudad de las sierras" 6 y "ciudad de la naturaleza", instauró un interés turístico que hizo mella en diversos sectores. Estas representaciones produjeron un fuerte proceso de especulación inmobiliaria y un boom de construcciones y nuevos emprendimientos que ocasionaron, al igual que la minería, tanto una fuerte presión sobre el ecosistema como un proceso de movilización y conflictividad social.

\footnotetext{
${ }^{5}$ Macizo de piedra que se formó geológicamente hace 2.500 millones de años. El sistema de Tandilia consiste en un conjunto de pequeñas "islas" rocosas que nacen en la pampa húmeda y se extienden en sentido NO-SE, desde Olavarría hacia la Costa Atlántica. Este recurso se encuentra cargado de sentidos culturales puesto que los ciudadanos de Tandil le otorgan una relevancia significativa en sus vidas y en el desarrollo de la ciudad.

${ }^{6}$ Para entender cómo el medio ambiente es apropiado y resignificado como elemento constitutivo de la producción simbólica de la vida urbana en la ciudad de Tandil véase Gravano (2005) y Silva (2010).
} 


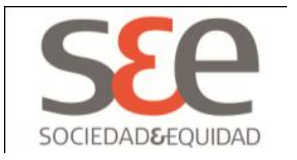

En este sentido, el conflicto socioambiental presente en la ciudad de Tandil permite vislumbrar, a través del estudio de los discursos y prácticas de los actores sociales, la disputa que se genera en torno a la "ciudad imaginada" y al tipo de desarrollo que se quiere para la misma. Al mismo tiempo, posibilita reflexionar respecto a la valoración del vínculo que la comunidad mantiene con los recursos naturales.

El comienzo de este proceso conflictivo se remonta a los años ' 70 , donde diversos sectores de la población local, al visualizar a la actividad extractiva como dañina y poco beneficiosa, se movilizaron y participaron activamente en el marco de ONGs y agrupaciones. Resulta necesario entender que la historia de Tandil se encuentra ligada al desarrollo de la explotación minera, similitud compartida con otras ciudades serranas de la región (Olavarría y Balcarce) ${ }^{7}$. En este sentido, la actividad de los picapedreros se inició a fines del siglo XIX y se constituyó rápidamente como una actividad relevante para la economía local. El auge de la explotación de la piedra se basó en la calidad del material granítico extraído en la zona, en la presencia de población inmigrante que proveía mano de obra especializada y experimentada en el oficio de la piedra y, fundamentalmente, en la cercanía y fácil traslado a los centros demandantes.

Sin embargo, como se mencionó, desde la década del '70 el impacto de la actividad extractiva en la comunidad tandilense ha generado un acalorado debate. Por una parte, la evolución y diversificación de la economía local implicó que la explotación de las canteras haya perdido importancia relativa en cuanto a ingresos municipales. Por otra parte, los cambios en el tipo de producto y las nuevas tecnologías utilizadas han provocado la connivencia de poca y especializada mano de obra con explotación intensiva y depredadora del recurso. Sumado a ello, el proceso de expansión urbana provocó la proximidad y visibilización de las metodologías extractivas y el impacto socioambiental de la actividad canteril. Estos cambios en la actividad extractiva estuvieron vinculados a los procesos macroeconómicos de los años ' 90 que impactaron fuertemente en la economía de Tandil, principalmente en el desarrollo de la industria metalúrgica y minera. De este modo, la búsqueda de alternativas económicas contribuyó a generar pequeños emprendimientos ligados al turismo, ponderándose la conservación de las sierras como recurso natural. Esta nueva explotación del recurso, sumado al uso extractivo de las sierras, permitió extender la conflictividad social y derivó en la conformación de una agrupación ambientalista en el año 2000, la Multisectorial por la Preservación de las Sierras de

\footnotetext{
${ }^{7}$ La ciudad de Tandil y Olavarría le otorga una significación diferencial a su perfil serrano: mientras que Olavarría transforma las sierras por acción del trabajo fabril, eje fundamental a partir del cual se construye y reconstruye la imagen de la ciudad, Tandil privilegia la naturaleza sin mediación humana puesto que incorporó a la identidad urbana el paisaje serrano (Boggi y Silva, 2007).
} 


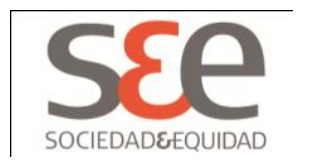

Tandil, cuya exigencia fundamental se relaciona con la declaración de las sierras como "Áreas Protegidas".

Ante este conflicto, los vecinos directamente perjudicados por la explotación minera reunieron más de 10 mil firmas para solicitarle al Municipio el cese de la actividad. Esta situación, sumada a las denuncias de la multisectorial por el incumplimiento reiterado de las empresas a las normativas de regulación ambiental y laboral, obligó al Municipio a buscar una solución de la problemática por la explotación minera mediante la sanción del Acuerdo Marco ${ }^{9}$, reconocido por el Estado provincial y nacional. Esta medida en lo inmediato posibilitó apaciguar la conflictividad social hasta que comenzaron a vislumbrarse las deficiencias del Acuerdo: la pérdida de fuentes laborales como consecuencia del cese de la actividad de dos canteras, la falta de estudios concretos que establecieran el impacto ambiental de la actividad, el incumplimiento de la condiciones para realizar las voladuras, y la interrupción en el pago del "derecho a la extracción de la piedra".

Con la asunción del intendente radical Miguel Ángel Lunghi en 2003, los sectores en conflicto visualizaron favorablemente la intención política de generar cambios en la gestión y explotación del cordón serrano. En consonancia con este clima comunitario, en el año 2005 se aprobó un nuevo Plan de Desarrollo Territorial (PDT) el cual estableció un Plan de Manejo Especial de la Zona Protegida "Sierras de

\footnotetext{
${ }^{8}$ La figura jurídica de Áreas Protegidas permite regular qué actividades se pueden realizar y cuáles no. Se prohíben los usos contrarios a la protección de las sierras. En el caso particular de Tandil, se prohíbe el uso minero y las construcciones (salvo lo estrictamente necesario para cumplir con los objetivos de conservación) y se permite el uso recreativo, cultural, educativo y turístico sustentable de las sierras. Para delimitar el Área Protegida se deberían utilizar al menos tres criterios: altura, pendiente y ecología. Quedarían incluidos cerros con cierta altura, desde los $220 \mathrm{mts}$., con pendientes fuertes, y aquellas áreas en la base de los mismos que constituyan hábitats de flora y fauna serrana. De este modo, la figura jurídica de Áreas Protegidas establece la necesidad de proteger la totalidad de las sierras, a diferencia del Paisaje Protegido, y posee una actitud más rígida respecto a los usos permitidos del recurso.
}

${ }^{9}$ El Acuerdo Marco se elaboró en el 2000. Los principios básicos que rigen su accionar son: respeto a la ley vigente, reconocimiento de los valores sociales, preservación del patrimonio ecológico, mantenimiento de las fuentes de trabajo, defensa de las tradiciones, y compromiso de satisfacer las legítimas necesidades de las generaciones presentes y futuras. A grandes rasgos, mediante el Acuerdo Marco se acordó la Mitigación del Impacto Ambiental generados por la actividad minera, la tasa del Derecho a la Extracción de la Piedra, la armonización de la actividad minera con la actividad turística, la creación de un Parque Minero para la relocalización a largo plazo de las canteras que se encontraban funcionando dentro de la poligonal. Sumado a ello, se establecieron días para la realización de las voladuras; las canteras debían presentar los Informes de Impacto ambiental y se generaría una comisión encargada de controlar los trabajos de mitigación y embellecimiento paisajístico de las zonas afectadas por la actividad. 


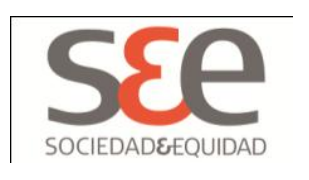

Tandil" para regular el uso, ocupación, subdivisión y equipamiento del suelo, al igual que determinar el sistema de gestión territorial. Sin embargo, las problemáticas de la explotación y construcción sobre el faldeo serrano continuaron siendo el foco de múltiples críticas. Como corolario de esta situación en el año 2006 se creó la agrupación ambientalista “Asamblea Ciudadana en Defensa de las Sierras", cuyo espacio permitió retomar y reorganizar la presión comunitaria en favor de la preservación del recurso. El accionar de este nuevo espacio sirvió para denunciar el poco impacto socioambiental del PDT y el incumplimiento de los plazos estipulados para la reglamentación del mencionado Plan de Manejo Especial de la Zona Protegida "Sierras de Tandil". La Asamblea, como referente ambientalista de la ciudad, perforó en el imaginario municipal de la "ciudad soñada" mediante diversas jornadas concientizadoras $y$, específicamente, una consulta popular ${ }^{10}$ sobre el interés comunitario de declarar las sierras como "Áreas Protegidas".

Asimismo, en el marco de este conflicto de intereses y perspectivas sobre la utilización, gestión y ocupación del sistema serrano, sectores de la oposición política elaboraron un proyecto de ley recogiendo parte de las históricas declamaciones de las agrupaciones ambientalistas. Si bien el proyecto fue gestionado por un senador tandilense del Frente Para la Victoria (FPV), una vez ingresado al Senado Provincial fue cooptado políticamente y enarbolado mediáticamente por el oficialismo radical. Finalmente, en el año 2010 se sancionó la "Ley de Paisaje Protegido" № 14.126. A diferencia del histórico reclamo tanto de la Multisectorial por la Preservación de las Sierras de Tandil como de la Asamblea Ciudadana en Defensa de las Sierras que exigían la declaración de las sierras como “Áreas Protegidas”, la medida legal sancionada estableció la prohibición de la actividad minera dentro de la zona denominada la Poligonal (intersección de las actuales Rutas Nacional $N^{\circ} 226$ y Provinciales $\mathrm{N}^{\circ} 74$ y $\mathrm{N}^{\circ} 30$ ), quedando al margen de regulación la explotación y depredación minera del resto de los sectores serranos que comprenden el partido de Tandil, como así también la construcción inmobiliaria en el faldeo de la totalidad de las sierras.

Las medidas legales implementadas, lejos de terminar o atenuar el conflicto por el uso, gestión y ocupación del sistema serrano, posibilitaron el resurgimiento del debate respecto a los usos del medio ambiente y a la distribución desigual de los beneficios $\mathrm{y}$ externalidades que generan determinadas actividades productivas $\mathrm{y}$

\footnotetext{
${ }^{10}$ La Consulta Popular se realizó el 19 de septiembre de 2009. Participaron más de 400 voluntarios, quienes recorrieron diversos barrios de la ciudad de Tandil con el objetivo de recabar la opinión de la ciudadanía respecto a la declaración de las sierras como Áreas Protegidas. En este sentido, 14 mil hogares se manifestaron de acuerdo en solicitarles a todas las autoridades responsables de la preservación de las sierras su declaración como Áreas Protegidas, para impedir por ley y sin excepciones la actividad minera, las construcciones y forestaciones exóticas sobre el sistema serrano.
} 


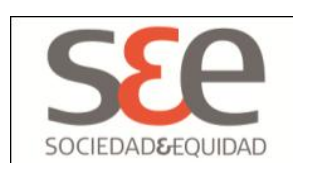

recreativas (minería, turismo y mercado inmobiliario). Si se analiza tanto el uso de los recursos ambientales que contempla la Ley de Paisaje Protegido como la falta de voluntad política para reglamentar el Plan de Manejo Especial de la Zona Protegida concerniente al PDT, se puede observar, por un lado, la sustitución de una actividad productiva por una recreativa tan nociva como su antecesora y el posterior desplazamiento de la explotación minera hacia zonas periféricas que no permitan contradecir la representación de "ciudad soñada" y, por otro lado, se puede percibir la discrecionalidad política con la cual el Municipio exprime los intersticios legales para otorgar excepciones inmobiliarias en el faldeo serrano.

El análisis concreto de la sanción de estas normativas en el ámbito más general de los procesos de movilización y conflictividad social, permiten tematizar que en la elaboración de políticas públicas se produce un juego de poder entre diversos actores sociales que intentan incidir, directa o indirectamente, en el curso de la formulación, aplicación y control de las medidas legales extendiéndose el campo de la acción política más allá de la esfera estatal y la institucionalidad formal del sistema político (Noé Echeverría, 1998). En el caso de estudio, la reglamentación de la Ley de Paisaje Protegido durante el año 2010, mediante el Plan de Manejo Ambiental ${ }^{11}$, generó repercusiones negativas en el sector minero y en aquellos vecinos que defienden la persistencia de la actividad. Este hecho permitió desvelar los conflictos que se producen como consecuencia de la separación entre los procesos de elaboración de políticas y sus aplicaciones. En esta reglamentación no existió una activa participación social de aquellos actores sociales involucrados directa o indirectamente en la problemática minera (propietarios mineros, transportistas y trabajadores mineros), sino que sólo trabajaron en su elaboración funcionarios municipales y provinciales, cientistas locales e, indirectamente, agrupaciones ambientalistas. En consecuencia, el Plan de Manejo Ambiental hizo mella en los mencionados actores, quienes no estuvieron directamente implicados, dando lugar a un recrudecimiento desestabilizador y mediático de la problemática socioambiental ${ }^{12}$.

\footnotetext{
${ }^{11}$ La formulación del Plan de Manejo Ambiental permite la administración del Paisaje Protegido, así como el procedimiento para la reconversión de las explotaciones mineras en funcionamiento y los mecanismos para regularizar la situación de los trabajadores pertenecientes a las canteras localizadas en la zona de la poligonal.

${ }^{12}$ El cese definido de la actividad minera dentro de la poligonal, establecido por el decreto de
reglamentación de la Ley de Paisaje Protegido $\mathrm{N}^{\circ} 14.126$ para el día 8 de Octubre de 2011 ,
generó que los empresarios canteristas, los trabajadores mineros y los transportistas se
resistieran a la medida y entraran en conflicto con el gobierno municipal durante el mes de
Septiembre. Estos actores instalaron por varios días sus camiones y acoplados en las calles
principales que rodean al Municipio de Tandil, como así también dispusieron una carpa y una
gran producción de banderas que daban cuenta de sus reclamos. Sin embargo, después de
diez días de paro, de una disputa interna en la sociedad que llevó a un apoyo masivo de la ley
} 


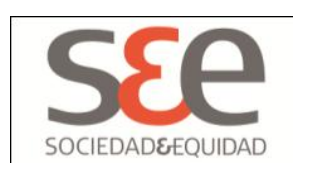

En términos generales, a partir del trabajo etnográfico realizado durante los años 2009-2011, el análisis del conflicto socioambiental en torno a la explotación y preservación de las sierras posibilitó visibilizar diferentes valoraciones y racionalidades referenciadas en tres grandes grupos de actores sociales: grupos de la sociedad civil (agrupaciones ambientalistas, vecinos pertenecientes a determinados barrios, representantes del "saber experto" y prensa local); actores y protagonistas del campo de la política municipal, provincial y nacional; y grupos con intereses económicos en juego (representantes del sector inmobiliario y del sector minero) ${ }^{13}$. Asimismo, el trabajo de campo fue abordado a partir de técnicas cualitativas del método etnográfico, como la observación participante y la entrevista no estructurada, que permitieron acceder al universo sociocultural de los actores involucrados.

Para comprender acabadamente los posicionamientos e intereses subyacentes al conflicto socioambiental, se deben mencionar distintos discursos que enmarcan las valoraciones y racionalidades puestas en juego por los actores. Si bien existe pluralidad de perspectivas respecto a la explotación/preservación del medio ambiente, predomina en sus discursos una visión instrumental de la naturaleza opuesta a una visión preservacionista de los recursos naturales.

Por un lado, aparece el reclamo de los vecinos, agrupaciones ambientalistas y ONGs interesadas en conservar el recurso sierras como un patrimonio natural y cultural de incuestionable valor geológico, estético-paisajístico, hídrico e identitario que excede lo netamente económico.

(...)cuando se empezó a luchar por las sierras hace unos años atrás pensábamos en las sierras como una, como un tesoro geográfico muy importante...las sierras de Tandil tienen un valor tan importante, queremos que las sierras sean para los tandilenses, para el turismo, que la gente de Tandil pueda ir a las sierras, que puedan ir a caminar, a tomar un mate como se hace (Fragmento de observación participante realizada durante la

de Paisaje Protegido, de una firme decisión del gobierno municipal y provincial para cumplir con lo reglamentado y del desgaste de los manifestantes, se concluyó con la protesta y finalmente el 21 de Diciembre de 2011 el gobierno provincial dispuso el cierre definitivo de las canteras ubicadas en la poligonal.

${ }^{13} \mathrm{El}$ análisis de los discursos y prácticas de los mencionados actores posibilitó abordar tres ejes relevantes de la problemática: lo político, lo económico y lo social. Empero, no se realizó un análisis aislado de cada aspecto sino que se indagó en la problemática desde una perspectiva que prioriza la concepción de sistemas complejos referenciada por Rolando García (1994). 


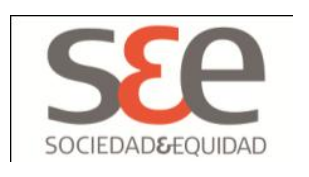

presentación del Plan de Manejo Ambiental de la Ley de Paisaje Protegido en el teatro municipal; declaraciones de ciudadana).

Todas las sierras de Tandil son valiosísimas, son pequeños y antiquísimos afloramientos precámbricos de extraordinaria importancia, albergan relictos de pastizal serrano y una notable biodiversidad, son cabeceras de cuencas hídricas, nacientes de los arroyos y área de recarga del acuífero del cual se abastece Tandil. Son nuestra identidad, nuestro patrimonio natural más preciado y una maravilla cuyo cuidado nos compete (Fragmento de entrevista realizada a miembro de la Asamblea Ciudadana en Defensa de las Sierras).

Por otro lado, se visualiza el reclamo del sector minero e inmobiliario quienes reconocen a las sierras como un recurso productivo, fuente de trabajo y lugar de residencia. En este sentido, cuestionan la protección extrema del sistema serrano fundamentando que la no utilización productiva y recreativa del recurso impide el desarrollo económico y social de Tandil.

Tandil creció en diferentes actividades, las ciudades crecen cuando vos cuidás tus actividades porque acá hay muchas actividades que por ahí contaminan más que la actividad minera, porque la contaminación de la actividad minera es visual (Fragmento de entrevista realizada a gerente de una cantera localizada dentro de la zona de la poligonal).

(...) en las canteras hay muchas raíces italianas, yugoslavas, españolas que venían de sus países de orígenes con el oficio de picapedreros y después los hijos, los nietos, son muchas generaciones que están trabajando actualmente en la cantera (Fragmento de entrevista realizada a trabajador minero de una cantera localizada dentro de la zona de la poligonal).

Somos partidarios de preservar el paisaje, las sierras, el agua, la flora y fauna, pero no de inmovilizar el suelo, de impedir el contacto o el disfrute de la naturaleza. El paisaje no es una fotografía inmóvil que se observa desde lejos sin tocarlo, sino un ambiente en el que se sumerge, se vive y se desarrollan actividades recreativas, económicas y culturales (Propietario de terreno localizado sobre faldeo serrano perteneciente al grupo "Vecinos por un Desarrollos Sustentable" expresándose en un medio de prensa local). 


\section{SEe}

Estos grupos de poder otrora favorecidos por la (des) regulación municipal actualmente interpelan al Estado respecto a su posicionamiento en el conflicto por la preservación de las sierras, disputando la legitimidad de los usos productivos y recreativos que realizan del recurso natural. En este sentido, cada sector confronta de manera diferencial con el municipio y la provincia. El sector minero reclamó ante la justicia la supuesta inconstitucionalidad de la Ley de Paisaje Protegido puesto que en la Argentina la actividad minera es lícita y depende de la provincia y nación. Al mismo tiempo, señalan que estas actividades se desarrollan sobre terrenos privados, impactan mínimamente en el medio ambiente y permiten generar nuevas fuentes de genuino trabajo.

(...) se piensa que las sierras son del Estado por eso se dice nuestras sierras, como podemos decir nuestro Tandil, nuestra provincia, pero son privadas, las canteras son actividades lícitas y legales (Fragmento de entrevista realizada a representante de Asociación Obrera Minera Argentina).

Por otra parte, el grupo de vecinos propietarios de terrenos serranos nucleados en la agrupación "Vecinos por un Desarrollo Sustentable" no ha iniciado acciones legales contra el Municipio, pero exigen la "flexibilización” de las medidas sancionas (PDT y Ley de Paisaje Protegido) para poder realizar subdivisiones en los inmuebles y disminuir las limitaciones a los usos del suelo, ya que entienden esta situación como un agravante contra los derechos básicos, más específicamente el derecho a la propiedad privada. Manifiestan que los usos inmobiliarios y turísticos no dañan a las sierras sino, por el contrario, aducen que permiten cuidar y embellecer el recurso, realzar las características de las sierras, generar una vista panorámica atractiva e impedir su degradación y su eventual ocupación.

Pedimos un plan racional que encuentre un punto de equilibrio que evite convertir a la zona en un área urbana pero haga posible su aprovechamiento por los tandilenses. Un cinturón de quintas es la mejor forma de preservar el ambiente, impedir su degradación y su eventual ocupación por intrusos (Propietario de terreno localizado sobre faldeo serano perteneciente al grupo “Vecinos por un Desarrollos Sustentable” expresándose en un medio de prensa local).

Las modificaciones legales en la gestión del recurso sierras no obedecen únicamente al pedido de la ciudadaníapor su preservación, sino que se asocian con el proyecto de ciudad que contempla e imagina el municipio. En este sentido, Tandil posee una economía diversificada, sin embargo, en los últimos años las actividades turísticas han adquirido mayor relevancia, evidenciándose una importante relación entre el 


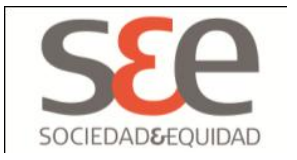

mantenimiento de las sierras (sus aspectos visibles) y el desarrollo económico. De este modo, detrás del discurso ambientalista que esgrime el Estado existe una serie de intereses políticos y económicos que obstaculizan la efectiva preservación del medio ambiente. El recurso serrano se establece como un elemento central para el armado de proyectos urbanísticos y turísticos porque conjuga el interés y especulación económica con la belleza y singularidad paisajística.

\section{Un Tandil reverdecido}

En general, los conflictos sociales habilitan la emergencia de diversos actores que buscan tensionar las estructuras vigentes mediante la puesta en escena de sus capitales simbólicos y racionalidades divergentes. De este modo, en el conflicto socioambiental investigado, se manifiestan posiciones y valoraciones diferentes en relación a la utilización de los recursos naturales, expresándose racionalidades que se oponen a la gubernamental y/o empresarial. Asimismo, la propia dinámica de oposición posibilita reflexionar respecto a los usos de los recursos naturales y socializar conocimientos en relación a las problemáticas ambientales debatidas. Podría interpretarse que el principal logro de estos conflictos no radica únicamente en la resolución de las problemáticas ambientales sino en la interpelación cultural que produce la propia conflictividad social a través de la exposición de otros conocimientos y prácticas que permiten un avance del ambientalismo, no como fuerza sino como conciencia.

Para Ascelrad (2004) es la lucha por la apropiación simbólica y la transformación de formas culturales la que, mediante un proceso de legitimación y deslegitimación de algunas prácticas, posibilita generar las condiciones para el cambio material, criticar concepciones arraigadas y garantizar procesos de revisión y resignificación.

En este sentido, las agrupaciones ambientalistas, ONGs y asambleas ocupan un rol fundamental en la lucha de la sociedad civil por generar cambios en la gestión ambiental y la elaboración de nuevos proyectos sociales y culturales. Posibilitan la construcción de valoraciones que articulan fragmentos de una "realidad alternativa", de otra "cosmovisión del mundo" desprovista de la concepción utilitaria capitalista. En el caso de estudio, la presencia de dos agrupaciones ambientalistas debe comprenderse a luz de la ambientalización más general de la vida social y de la creciente resistencia ciudadana a determinados usos del recurso sierras. Desde la década del ' 70 las mismas vienen reclamando el control o erradicación de la actividad minera, las construcciones sobre el faldeo serrano $y$, sobre todo, la declaración de las sierras como "Áreas Protegidas".

Si bien es probable que en términos de resultados la persistencia de las mencionadas problemáticas pueda leerse como una derrota para la posición ambientalista, el impacto de la actividad minera y el avance vertiginoso de las 


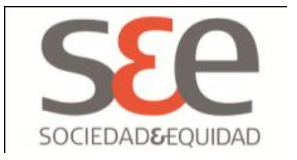

construcciones sobre las sierras, sigue siendo el leitmotiv de la militancia ambientalista que ha crecido constantemente en adhesión comunitaria. Un claro ejemplo de esta situación se vivenció cuando las canteras afectadas por la Ley de Paisaje Protegido se negaron a cumplir con el decreto de reglamentación que establecía el cese definitivo de la actividad minera. En respuesta a este incumplimiento, diversas instituciones, ONGs, vecinos y dirigentes sociales de Tandil expresaron la adhesión al estricto cumplimiento de la ley a través de carteles elaborados por el gobierno municipal que empapelaron toda la ciudad: "Nosotros decimos NO por nuestro patrimonio más valioso, por nuestro futuro, por nuestro Tandil, por nuestra calidad de vida, por nuestra identidad, por las próximas generaciones, ni una explotación más que destruya nuestras sierras. Nosotros decimos Sí al cumplimiento de la Ley de Paisaje Protegido de nuestras sierras".

Como sostiene Martínez Alier (2005), los conflictos socioambientales no sólo son conflictos de intereses sino también de valores. Los sectores movilizados, principalmente las agrupaciones ambientalistas y representantes del sector minero e inmobiliario, están reclamando una restructuración de las relaciones de poder con el objetivo de evitar que un grupo de actores específico imponga sobre los conflictos un determinado lenguaje de valoración para juzgar. Del mismo modo, diversos profesionales están comenzando a involucrarse en estas temáticas desde una postura más crítica y comprometida. El análisis del discurso de los actores participantes en los conflictos socioambientales posibilita entender los lenguajes de valoración empleados, las representaciones y significados que connotan sus expresiones. En este sentido, se trata no sólo de una cuestión discursiva sino de la manera de comprender el mundo y, específicamente, la relación social con la naturaleza; por ejemplo: el concepto de patrimonio empleado por las agrupaciones ambientalistas de Tandil reconoce a la naturaleza como sujeto de valor, remite a la idea de legado para los hijos, entiende a la conservación del ambiente como un fin en sí mismo y abre la posibilidad para la regulación social de los recursos y del mercado (Gudynas, 2004).

Existe una compleja relación entre el orden simbólico y el orden natural que conlleva a la producción de diversas racionalidades sobre el uso, gestión y ocupación del sistema serrano, dando cuenta de los distintos vínculos que los actores sociales construyen con su entorno natural. La contraposición entre racionalidades supone evaluar y comparar alternativas entre diferentes tipos de producción: extractiva o no extractiva, sustentable o no sustentable, e implica una oposición entre dos dimensiones temporales, una acotada al presente y otra proyectada hacia el futuro (Fernández, 2007).

En este sentido, resulta menester detenerse brevemente en el posicionamiento del Estado municipal en el conflicto socioambiental. La incorporación de elementos de racionalidad ambiental en las dos gestiones del intendente Lunghi (2003 a la actualidad) se materializó en la creación de una 


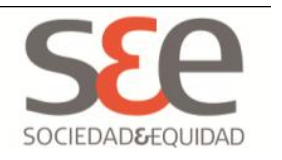

Dirección de Medio Ambiente y en la sanción de las mencionadas medidas legales. Sin embargo, la vigencia y defensa de la racionalidad económica muchas veces aparece disfrazada en los discursos de los funcionarios políticos manifestando el cuidado del medio ambiente como consigna unívoca y sin contradicciones, pero legitimando a través de los resortes municipales la apropiación privada y sobreexplotación de los recursos naturales. Es a nivel micropolítico donde se expresan claramente las arenas de disputas en torno al medio ambiente, los efectos negativos de la racionalidad capitalista y sus procesos de producción, distribución y consumo.

Diversos sectores (agrupaciones ambientalistas y vecinos perjudicados por la explotación minera y construcción inmobiliaria en las sierras) de la comunidad tandilense han agudizado su crítica y desconfianza a las intervenciones y nointervenciones estatales, visualizando la existencia de una amalgama de intereses que obstaculizan la solución de las problemáticas ambientales y que contradicen los pedidos de la población. Critican los "maquillajes verdes" que el municipio adquiere, la deficiente promoción de formas de planificación y gestión ambiental, y la falta de espacios de participación y apertura política para los sectores implicados en el conflicto. En suma, lo que más critican es que no se pueda formar parte del proyecto de ciudad que se intenta construir preservando y controlando legítimamente los propios recursos naturales. De este modo, es posible vislumbrar cómo dentro de esta trama conflictiva las relaciones de poder son las que determinan qué tipo de racionalidad, explotación y desarrollo finalmente prevalecerá.

\section{Consideraciones Finales}

La gestión estatal del medio ambiente en la Argentina se desarrolla en base a una historia de conflictos, negaciones e intermitencias en las políticas públicas. El surgimiento de numerosas crisis socioambientales dio lugar a un sinnúmero de movimientos sociales, conflictos y resistencias que se han desplegado en los últimos años a lo largo del territorio nacional.

En lo que respecta a la explotación y preservación de las sierras de Tandil, están en disputa aspectos adyacentes al cuidado del medio ambiente. El eje de la discusión es el derecho de las personas tanto a decidir cómo deben utilizar sus territorios como a la posibilidad de participar en la distribución de los costos y beneficios generados por ciertas actividades productivas y recreativas, intentando impedir determinados usos nocivos del medio ambiente.

Actualmente el interrogante entre los actores en conflicto es: sierras para qué y para quién. Esta situación permite repensar el creciente proceso de urbanización que ha repercutido diferencialmente en la apropiación del suelo y los recursos de la ciudad. Al mismo tiempo permite debatir el rol del Municipio respecto a la regulación del recurso, puesto que no existe una efectiva preservación de las sierras. 


\section{S\&e \\ SOCIEDADEEQUIDAD}

El análisis del conflicto se centró en su etapa de desarrollo porque aún no se alcanzó una resolución definitiva. La explotación/conservación de las sierras fue resignificándose y adquiriendo nuevas aristas a partir de los intereses políticos y económicos que gravitan en el manejo del medio ambiente, demostrando que no existe un único lenguaje ni una única manera de imaginar el desarrollo futuro de la ciudad.

En este sentido, resulta difícil proyectar el posible desenlace del conflicto, ya que este fenómeno relativamente reciente todavía tiene mucho por tematizar respecto a qué ciudad se quiere construir y qué tipo de racionalidad debería imperar. Sin embargo, la investigación permitió develar que cientos de vecinos de la población local se resisten a contemplar pasivamente la degradación del recurso natural sierras $y$, sobre la base de sus condiciones materiales de existencia, intentan participar e intervenir en la gestión, utilización y ocupación del sistema serrano. Quizás, como lo expresa Galeano, "la utopía está en el horizonte. Camino dos pasos, ella se aleja dos pasos y el horizonte se corre diez pasos más allá. ¿Entonces para qué sirve la utopía? Para eso, sirve para caminar" (Galeano, 1993:230).

\section{Referencias Bibliográficas}

Alimonda, Héctor (2008). Introducción. En Gestión ambiental y conflicto social en América Latina (pp 13-21). Buenos Aires: CLACSO.

Ascelrad, Henri (2004). Conflitos ambientais no Brasil. Rio de Janeiro. Fundación Heinrich Boll.

Aval Medina, Juan Manuel (2006). Crisis y recomposición del Estado. Revista Argentina de Sociología, V. 4, № 7, Julio/Diciembre 2006: 140-150.

Boggi, S. y Silva, A. (2007, Octubre). Imaginarios urbanos entre el ser y el devenir. Los casos de la 'Galera' en Olavarría y la Piedra Movediza en Tandil. Ponencia presentada a las XI Jornadas Nacionales de Investigadores en Comunicación, Mendoza, Argentina.

Castells, Manuel (1998). El enverdecimiento del yo: el movimiento ecologistas. Revista digital La Factoría, № 5, Febrero-Mayo 1998: 1-20.

Castells, Manuel (1987). Movimientos sociales urbanos. México: Siglo Veintiuno Editores. 


\section{SEe}

Cotarelo, María Celia (2005). Recursos naturales y conflicto social en la Argentina Actual. Observatorio Social de América Latina (OSAL), №17, Mayo-Agosto2005: 6777.

Cotarelo, M.C. e Iñigo Carrera, N. (2004). Algunos rasgos de la rebelión en Argentina 1993-2001. Centro de Documentación y Estudios Latinoamericanos (PIMSA), Documento de Trabajo $\mathrm{N}^{\circ} 49$.

Cucó Giner, Josepa (2004). Antropología Urbana. Barcelona: Editorial Ariel.

Dávila Paredes Tania (2010). ONG y Estado. Participación, rivalidad y cooperación en la gestión ambiental. Quito-Ecuador: Ediciones Abya- Yala.

Dipaola, Néstor (2003). La ciudad de las Sierras. Reseña histórica del Tandil. Tandil: Ediciones Chapaleofú.

Fernández, Roberto (2000). La ciudad verde. Teoría de la gestión ambiental urbana. Ciudad Autónoma de Buenos Aires: Espacio editorial.

Fernández Equiza, Ana María (2007). Análisis interdisciplinar de la valoración de la naturaleza en los conflictos ambientales. Tesis de Doctorado no publicada. Universidad Federal de Santa Catarina, Brasil.

Galeano, Eduardo (2004). Úselo y Tírelo. El mundo visto desde una ecología latinoamericana. Buenos Aires: Grupo Editorial Planeta.

Galeano, Eduardo (1993). Las palabras andantes. Buenos Aires: Catálogos S.R.L.

García, Rolando (1994). Interdisciplinariedad y sistemas complejos. En Enrique Leff (comp.), Ciencias Sociales y Formación Ambiental (pp 85-124). Barcelona: Editorial Gedisa.

Godelier, Maurice (1989). Lo ideal y lo material. Pensamiento, economías, sociedades. Madrid: Taurus Humanidades.

Gravano, A. (2005, Julio). La Antropología Organizacional y la circularidad en la planificación: el caso del TOAR. Ponencia presentada en el Primer Congreso Latinoamericano de Antropología, Rosario, Argentina. 


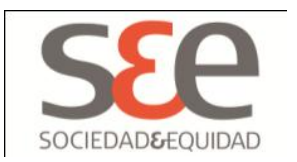

Gravano, Ariel (comp.) (2005). Imaginarios sociales de la ciudad media. Emblemas, fragmentaciones y otredades urbanas. Estudios de Antropología Urbana. Tandil: Centro Editor de la UNICEN.

Gudynas, Eduardo (2004). Ecología, economía y ética del Desarrollo Sostenible. Montevideo: Coscoroba ediciones.

Gudynas, Eduardo (1998). Globalización, políticas sociales y medioambiente. Revista Tareas, Centro de Estudios Latinoamericanos (CELA), Vol. 98, Enero-Abril: 23-44.

Leff, Enrique (2008). Discursos sustentables. México: Siglo Veintiuno Editores.

Leff, Enrique (1986). Ecología y capital. Racionalidad ambiental, democracia participativa y desarrollo sustentable. México: Siglo Veintiuno Editores.

Leite Lopes, José Sérgio (2006). Sobre processos de 'ambientalização' dos conflitos e sobre dilemas da participação. Revista Horizontes Antropológicos. Antroplogia e meio ambiente, $\mathrm{N}^{\circ}$ 25, Janeiro-Junho 2006: 31-64.

Martinez Alier, Joan (2005). El ecologismo de los pobres: Conflictos Ecológicos y lenguajes de valoración. Barcelona: Editorial Icaria.

Martinez Alier, Joan (1997). De la economía ecológica al ecologismo popular. Barcelona: Editorial Icaria.

Martinez Alier, Joan (1995). Los principios de la Economía Ecológica. Madrid: Fundación Argentaria-Visor distribuciones.

Martinez Alier, Joan y Klaus Schlüpmann (1991). La ecología y la economía. México: Fondo de Cultura Económica.

Noé Echevarría, Marcela (1998). Ciudadanía y Políticas Públicas. En Enrique Correa y Marcela Noé Echevarría (comp.), Nociones de una Ciudadanía que crece (pp 38-60). Chile: FLACSO.

Orellana, René (1999). Conflictos ¿sociales, ambientales, socioambientales? Conflictos y controversias en la definición de conceptos. En Pablo Ortiz (Ed.), 


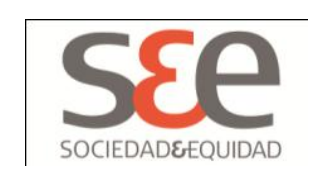

Comunidades y Conflictos socioambientales. Experiencias y desafíos en América Latina (pp331-344). Quito: Abya-Yala.

Sabatini, Francisco (1997). Chile: conflictos ambientales locales y profundización democrática. Revista Ecología Política, № 13, Abril 1997:51-70.

Sarlingo, M. (2008, Agosto). Los residuos como objetos. Ponencia presentada en el IX Congreso Argentino de Antropología Socia: “Fronteras de la Antropología”, Misiones, Argentina.

Sarlingo, Marcelo (2001). ¿Ser o parecer Verdes? Conflicto y reproducción: la política ambiental de la provincia de Buenos Aires en los años 90. Tesis de Doctorado no publicada. Facultad de Filosofía y Letras, Universidad de Buenos Aires, Buenos Aires.

Scribano, Adrián y Federico Schuster (2001), Protesta social en la Argentina de 2001: entre la normalidad y la ruptura. Observatorio Social de América Latina (OSAL), Septiembre 2001:17-22.

Silva, Ana (2010). Imágenes e Imaginarios Urbanos en la "Ciudad de las Sierras". Revista lluminuras, Ambientes e Ambiências - paisagens do mundo contemporâneo Sumário, V. 11, № 26, 2010:1-21.

Svampa, Maristella y Mirta Antonelli (2009). Minería transnacional, narrativas del desarrollo y resistencias sociales. Buenos Aires: Editorial Biblios Sociedad.

Walter, Mariana (2009). Conflictos ambientales, socioambientales, ecológicos distributivos, de contenido ambiental...Reflexiones sobre enfoques y definiciones. Boletín de Centro de Investigación para la Paz (CIP-Ecosocial), $\mathrm{N}^{\circ} 6$, Febrero-Abril 2009:1-9. 